\title{
Boundaries and transborder relations, or the hole in the prison wall: On the necessity of superfluous limits and boundaries
}

\author{
Walter Leimgruber \\ Department of Geosciences, Geography Unit, University of Fribourg/Switzerland, Chemin du Musée 4, CH-1700, \\ Fribourg, Switzerland (E-mail: walter.leimgruber@unifr.ch)
}

Key words: boundaries, geography of advantage, transborder cooperation

\begin{abstract}
Boundaries can be seen as barriers or as places of contact. It has been suggested that we are "prisoners of borders", of all kinds of borders (political, religious, social, cultural, linguistic etc.). While this statement appears to be somewhat exaggerated, it holds some truth. Boundaries are elements in spatial organization, and they influence daily life in many ways (not only for people living right along them). The paper addresses the question if we must call ourselves "prisoners" or if we simply have to live with all kinds of borders. Departing from theoretical observations, the paper discusses the various aspects boundaries assume in the European context before looking at a few concrete Swiss examples. They reveal that even regions at a certain distance of the state border will feel its effects (the case of Zurich airport), but the most important benefit can been drawn by people living in the border area itself (through price differences between the two countries, as exemplified by the Swiss-Italian border). There may be asymmetry on state borders, but this asymmetry can also swing around: the advantages often lie on both sides. The paper concludes by pointing to the persistence of the boundary concept. They are a necessity for the organization of space and society, but they are not absolute. There are always holes in these prison walls, and the examples where boundaries were impermeable are probably rare.
\end{abstract}

\section{Introduction}

The discussions about political boundaries have always oscillated between two perspectives: they were seen either as barriers or as places of contact (Mrohs and Heukels, 1970), as obstacles or potentials. Marking the edge of a state (of a political zone of influence) has been their main function, and they continue to do so despite many efforts to overcome this separating role. Their importance in the state-building process has been illustrated after the end of the Soviet Union and of Yugoslavia (see, for example, Hajdú, 2004). Yet, the growing global interdependence, based on internet and e-mail, world trade, global capital flows, and common social and environmental problems suggest that boundaries are doomed to disappear or at least to be considerably weakened due to the necessity of transborder regional cooperation (Lee and Bahrin, 1998). The creation of the Schengen area inside the European Union, where border controls have been eliminated, seems to highlight this kind of process, which started just two generations ago.

Boundaries are conceived of as lines separating entities from each other. As such they create and refer to discontinuities. Such entities can be states or provinces, but also cultures, scientific fields, ways of thinking and other domains - there is no reason to limit this term to the political field alone (as will be done hereafter). Besides, apart for serving practical purposes, boundaries also have a profound psychological significance. It may be described by the term territoriality, "a primary geographical expression of social power" (Sack, 1986, p. 5). The necessity to control and defend one's sphere of influence can probably be seen as archetypical in the animal realm (including humans). Territories are delimited by boundaries, which, therefore, act as elements of spatial differentiation. Depending on the degree of separation, they can be felt as almost non-existent or as a sort of prison wall, shutting a territory off from the rest of the world. The Berlin Wall, the Iron Curtain, and the US-Mexico border furnish the best-known examples for this latter image.

The invitation to a conference on boundaries in Europe (held in 2004) suggested that people could be seen as prisoners of borders. This latter term was used in a wide sense to include political, religious, social, cultural, linguistic boundaries. However, "prisoners of borders" is not the same as the border as a prison wall. A prisoner is first and foremost a person that for some 
reason or another has been confined to a limited space (a prison) and has restricted freedom of action. An external authority, a tribunal, has decided upon this confinement. From a psychological perspective, however, a prisoner is a person that is caught within a limited world (the ego, the senses), within a restricted framework of thinking, for example, who cannot go beyond his or her limitations. This is a sort of internally decided confinement.

This perspective is illustrated by a saying attributed to Albert Einstein: "A human being is part of a whole, called by us the 'Universe,' a part limited in time and space. He experiences himself, his thoughts and feelings as something separated from the rest - a kind of optical delusion of his consciousness. This delusion is a kind of prison for us, restricting us to our personal desires and to affection for a few persons nearest us. Our task must be to free ourselves from this prison by widening our circles of compassion to embrace all living creatures and the whole of nature in its beauty" (http://www-gap.dcs. st-and.uk). Humans are prisoners of their minds, and Einstein demands them to break through such prison walls.

The title of this contribution must therefore be understood from a figurative perspective: humans become prisoners once they are glued to a particular idea (a stereotype) and do not see the alternatives around us - they suffer from "monocultures of the mind" (Shiva, 1993) and cultivate "the TINA (there is no alternative) syndrome" (Shiva, 1996, p. 298). Persons who can only survive if they receive precise directives are prisoners of regulations. By writing down laws, a society creates rules of conduct that can become a sort of prison unless they keep pace with the dynamics of life. Individuals breaking these rules will usually marginalize themselves; however, they can also point the way to the expansion, re-interpretation or development of such self-constructed prison walls.

A number of questions turn up at this point. Are we prisoners of borders, and if yes, is this a negative fact? Can boundaries and limits really be abolished? Are they not a natural phenomenon humanity has to live with, that does not only restrict but also offers possibilities, alternatives? Many boundaries have been torn down, but new ones have been erected - it seems to be an ongoing process. There is no such thing as a borderless world; we have to live with all kinds of limitations and restrictions such as are imposed on us by our own nature, the ecosystem, our role as zoon politikon, as social beings in a human community within the ecosystem. Whether such limitations are prison walls is a matter of personal perception.

This essay looks at the prison defined by political boundaries whose walls have holes, indeed need holes. The prison wall metaphor addresses the fact that borders (not only political but of all kind) are at the same time inevitable and unwanted. This dichotomy is not really a contradiction but rather the two sides of the same medal. The focus will be on Europe, in particular on Switzerland (an island in the European Union). This country offers a good example for this ambiguity, because it is oscillating between participating in and standing outside the EU project.

\section{Theory and concepts}

In order to provide a solid basis for the case studies below, this section spells out the roles and effects of boundaries. In addition, it addresses the issue of border typology and links it to the topic of border effects.

\section{The functions and effects of boundaries}

The study of boundaries has to depart from the roles they assume, the border functions. In their pioneering book, Guichonnet and Raffestin (1974, pp. 48-53) distinguish between five different border functions:

1. The legal function: the border delimits the perimeter of laws and regulations, and of the judiciary. It is the circumference of the state territory where the political system exercises authority. This function would persist, even once all other functions had disappeared (ibid., p. 50).

2. The fiscal function is an instrument of economic policy, enabling the state to protect its economy against foreign competition. The best-known aspect is the duty, levied by the customs authorities. "This function is at the origin of numerous indirect border effects" (ibid.). At the same time it is an important source of income for the state.

3. The control function is destined to administer access to a country. People and goods can be submitted to simple checks or substantial scrutiny, depending on the regime or a specific context. This function is a policy instrument, concerning immigration (right of access, health issues) and trade (quality and quantity control), sometimes also on the transfer of information (censorship) - it acts as a filter (ibid., p. 51).

4. The military function emphasizes the boundary's role in national defence. It is true that the strategic situations and the new arms technology have considerably weakened it, but it still maintains a certain amount of relevance - border conflicts or wars have not disappeared.

5. The ideological function has most prominently been exemplified by the Iron Curtain, but it can also be detected in the everyday domain of schooling. Every country is convinced of the supreme quality of its school system, to go to school in the neighbouring country (because the school is closer) is almost impossible, at least as far as compulsory education is concerned. The border thus plays an important role in the building of national identity (Knippenberg and Markusse, 1999, p. 7).

In a dynamic world, these functions will not be static but subject to constant change. They may eventually disappear; more likely, however, they will be reduced in 
their effect - the two authors call this process defunctionalization.

Defining boundaries obviously creates various impacts on the landscape and the people. Again we have to resort to Guichonnet and Raffestin (1974, p. 45 f.) whose simple typology distinguishes between direct, indirect, and induced effects (for more details see Raffestin et al. (1975, p. 12). Similarly to the functions, the effects are also of a dynamic nature.

Direct border effects can be recognized in the doubling of infrastructure and industry investments. Schools, health institutions, bank and insurance offices are subject to national legislation; roads and railways are of national strategic importance (both economically and militarily). Industrial investment may be necessary to gain market access over an excessive fiscal function. To overcome such direct effect requires well thought-out bilateral agreements. Direct effects are highly localized; they concern the immediate borderlands.

Induced border effects are those material installations that are related to the various border functions: customs houses, border markers, fences etc. They are fairly stable, although following defunctionalization they may disappear or be put to other uses. This process can be observed in various crossing points on the border between France and Germany. Induced effects are highly localized (to be found on the boundary line itself and at the crossing points), but they may sometimes be felt in the hinterland when the border police install roadblocks at some distance from the boundary.

Indirect border effects mainly result from the existence of the fiscal function (see above). They include commuting, shopping, leisure activities etc. - they represent the geography of advantages. Indirect effects vary according to the economic and political situation, i.e. on factors such as inflation, exchange rates, price and tax policy, quantitative restrictions, sanitary regulations etc. They, too, are spatially limited in extent, although much less than the other two effects. Formal border zones for commuters usually cover a stretch of 10 or $20 \mathrm{~km}$ parallel to the boundary, but in an epoch of almost unbounded mobility, such limitations are illusionary.

\section{Problems of classification}

Boundaries or borders (the two terms will be used as synonyms in this context) can be classified according to various criteria, e.g. their type of separation, their hierarchical degree of separation, psychological or evolutionary aspects (Leimgruber, 1980, p. 67 f). Foucher (1988) evokes what he calls "false dilemmas", which can also be seen as a sort of classification: natural vs. artificial boundaries (p. 9), good vs. bad border lines (p. 10), arbitrary vs. conventional ways of delimitation (p. 11), colonial and national boundaries (p. 12), line and zone (p. 13), unique vs. diverse concepts of boundaries (p. 15). Morehouse (2004, pp. 23-28) proposes various perspectives on boundaries that can be seen as barriers, filters, expression of nationalism, points of conflict, points of contact and cooperation, or, historically, as reflecting natural law. To these reductionist approaches she adds the contextual one, representing "a movement away from reliance on global, generalizable laws and toward a focus on material conditions in the real world" (ibid., p. 28). Boundary studies therefore have to consider "social, political, economic, and ecological contexts as significant factors in any explanation of the processes of spatializing difference" (ibid.).

The Dutch researcher Van Houtum (1998) takes another perspective. He discusses four different viewpoints that are in reality opposing pairs of characteristics. They evoke the image of extremes at the end of continua (Figure 1). While the first of these two pairs obviously lies outside our considerations (boundaries are human, social creations, which may under certain circumstances be defined as following natural markers or lines), the other three merit attention.

\begin{tabular}{|lr|}
\hline & \\
natural & artificial \\
functional & affective \\
concrete & abstract \\
open & closed \\
\hline
\end{tabular}

Figure 1. The border continua (after Van Houtum, 1998, p. 13).

Affective borders reflect people's emotional ties with a given territory, whereas the functional aspect refers to the jurisdictional side (Van Houtum, 1998, p. 23). They correspond to concrete borders, whereas abstract borders are of a cognitive nature and "have been mentally conceived by people" (ibid., p. 39).

The idea of the hole in the prison wall is obviously contained in the last pair and can be related to the centripetal attitude of the political system (containment, protection) versus the centrifugal propensity of the economy (exchange, conquest of markets). Politics with its centripetal outlook regulates the daily life of its respective society, and these regulations are valid in the territory for which a given political system assumes responsibility. Although the idea of the global village suggests that borders are open and no longer present obstacles, the reality is very much different. The persistence of the political view thus guarantees the continuation of direct and induced border effects (Figure 2).

Tradition is very strong in this field, and even the European Union has not managed to eradicate this view within its member countries; rather has it added a further centripetal dimension, that of the Union as a whole. It is true that the nationalist perspective has slightly receded, due to the efforts of the past 50 years, but the walls have not been torn down completely, and they are likely to continue to exist. At the same time, the EU is busy building new prison walls at its periphery (Leuthardt, 1999) where holes will be very small and difficult 


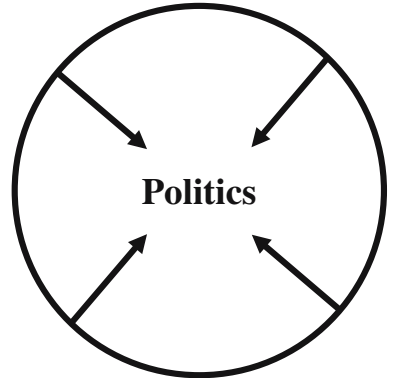

Direct border effects: infrastructure (national perspective), ideology, national identity

Induced border effects: protection, control

Figure 2. Centripetal politics and border effects (based on Leimgruber, 1999, p. 199)

to cross. Worldwide, new walls (material and not) are constantly being erected, emphasizing the dynamic nature of boundaries.

The second half of the 20th century has been hailed as an epoch where borders have almost completely disappeared. However, this is only partially true. It holds good to some extent for the internal borders of the European Union, in particular for the Schengen area with the possibility of free circulation, of which the population can draw considerable benefits. However, from the existence of borders results the geography of advantage, as we can call it. Reducing or suppressing border control enables people to profit of price and salary differences on either side of a political boundary. From this can be inferred a border advantage model (Leimgruber, 1999, p. 204), reflecting this situation and demonstrating the persistence of indirect border effects (Figure 3).

Systematic defunctionalization of boundaries with direct positive results for the individual customer has occurred in Europe only. Elsewhere, truly centrifugal economic exchange is restricted to the macroeconomic level. ${ }^{1}$ It usually takes the shape of free trade agreements between a number of states and is primarily intended for the national economy. The centrifugal philosophy of the economy has managed to downgrade the fiscal and (in part) the control function of the boundary. Free trade has become a sort of magic word of the late 20th century, but its benefits tend to disappear in the pockets of the intermediaries instead of fully trickling down to the individual customer. The creation of the WTO in the mid-1990s marked the climax of the international efforts to liberalize trade and create equal conditions for all suppliers around the globe - but what about the customers?

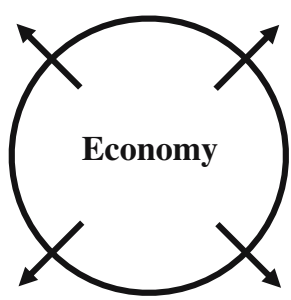

Indirect border effects The geography of advantage: salaries, prices, range of goods, quality, availability, ...

Figure 3. Centrifugal economy and border effects (based on Leimgruber, 1999, p. 199).

\section{The diversity of limits and boundaries in Europe}

In his manual on political geography, Pounds (1963, p. 29) has published a map showing the age of the European state borders. It reveals that most boundaries are in fact relatively young, that only a few (e.g. between Spain and Portugal, most of the Pyrenees, the Dutch border, and nearly the entire Swiss boundary) have existed unchanged for more than 400 years. Four decades after his book, Europe's political map has changed dramatically: many new state boundaries have been added after the collapse of the Soviet Union and former Yugoslavia. This is another witness to the dynamic nature of boundaries. Pounds' map furnishes a continental picture, but at this scale it has to omit the many internal boundaries that have disappeared when the modern state system was built in the 19th century. Following the unification of Italy ${ }^{2}$ and Germany in the 19 th century, former state borders have given way to uniform political systems; the creation of the Swiss Confederation in 1848 replaced a still very much fragmented union of independent states by a federation; abolishing internal customs and cantonal currencies was a major achievement that immediately benefited every single citizen.

The age and persistence of boundaries is one element when one speaks of their diversity, the degree of separation is another. State borders separate political systems, but these are far from homogeneous. The Franco-German boundary separates a centralist from a federalist (decentralized) system; in the former, all transborder affairs even on the provincial level are dealt with by the Ministry of Foreign Affairs in Paris, whereas in the latter, the individual Bundesländer dispose of some competence of their own in this field. Viewed from the inside, therefore, the same boundary is not the same considering transborder relations. To breach a hole is far easier for the Germans than for the French.

The foundation of the European Economic Community in 1957 laid the basis for the gradual defunctionalization of European boundaries. This process reduced the separating role in fields like national sovereignty, control, state revenue, ideology and military defence. Within the same continent, we witnessed on the one side the downgrading of the boundaries, while at the same time the iron curtain between the two ideological systems was constructed and reinforced, and "walls" between the members of the eastern bloc were raised.

In this same period, the border effects varied across Europe. Of the three types of effects (direct, indirect, and induced), the first and the third were reinforced along the Iron Curtain (doubling of infrastructures, construction of security posts), whereas the second (shopping trips, transborder commuting) was impossible to realize. Border control and demarcation became very strong (induced effects), and territorial development radically changed on either side (direct effect). Transborder relations in order to draw advantages of the border situation (indirect effects) were prohibited. The 
boundaries in Western Europe, on the other hand, experienced an ambiguous process of defunctionalization. There was a strong evolution of indirect border effects (increase in transborder commuting, shopping trips, capital flows etc.), but nationalist considerations continued to dominate in the field of direct effects (parallel infrastructures thanks to centripetal legislation in education, health services, police). The induced effects began to fade as border installations were gradually removed or put to new uses.

Deconstructing the political boundaries has not automatically conducted to the disappearance of disparities, as a few examples may demonstrate. The Iron Curtain still lives on to some extent in the mind of the Germans. Unemployment and job opportunities still differ between the Länder of the former GDR and FRG (in 2004, for example, unemployment amounted to $9.4 \%$ in the former FRG, but to $20.1 \%$ in the old GDR, which gives an average of $11.7 \%$ for Germany as a whole). The linguistic divide continues to characterize Europe, although learning other languages of the EU has become more popular and the EU actively encourages language learning: "Learning one lingua franca alone is not enough. Every European citizen should have meaningful communicative competence in at least two other languages in addition to his or her mother tongue" (EU, 2003, p. 4). The Entente Cordiale of 1904 has contributed to the downgrading of AngloFrench differences, although President de Gaulle's refusals in 1963 and 1967 to accept the UK as a member of the EEC has cast some temporary shade on this friendship. The argument that Britain was not mature enough to accept the Community's discipline (Rambaud, 2004) was not particularly friendly. The decision of the UK not to introduce the Euro but keep the Pound Stirling as national currency illustrates the persistence of the Channel as a divide inside the Union. Similarly, the backing of the US intervention in Iraq in 2003 illustrates George Orwell's geopolitical scenario: the UK is still part of Oceania, not of Eurasia (Orwell, 1954).

When discussing European boundaries, one often forgets that the continent is crisscrossed by more than just political boundaries. The slogan "Europe of the Regions" points to the existence of dividing lines that go beyond pure state borders. The internal organization of the individual countries, whether members of the EU and EEA or not, is characterized by perimeters of administrative and/or political significance. Europe is a culturally diverse continent with a considerable range of languages and religions, various regional and local histories, and many folk traditions. Attitudes towards the "others" are not the same everywhere, and the borders in the minds are stubborn constructs. All too often, these borders are more difficult to overcome than those drawn according to international treaties, and they impede the free movement of the people because they are also present in the minds of politicians and civil servants.

\section{Boundaries - the everyday reality of the Swiss}

Switzerland is an island in the sea of the European Union, and the Swiss border is by definition one of the EU's external boundaries. The association of the country to the Schengen accord, decided upon by a referendum in 2005, does not change this fact. Popular perception, however, has been different, because of excellent neighbourhood relations border controls were sporadic and random rather than systematic. As a result, a feeling of borderlessness had evolved and people tended to forget the control function of the international boundary. Even with good neighbours, however, problems may turn up, as the examples of the German border controls in 2004 and the dispute about the Zurich airport landing-regime demonstrate.

\section{Border problems with Germany}

In March 2004, the German border police suddenly considered the German-Swiss border as an external boundary of the EU and stepped up the control of incoming traffic. Where the travellers were usually just waved through, cars were stopped, the drivers had to show their papers, and the cars were at times meticulously searched. No explanations for this sudden tightening of measures were given except that it was a routine measure related to the Schengen treaty. The consequences were disastrous and were felt in different domains: people crossing the border regularly (for work or for shopping) were exasperated, road traffic directed towards Germany came to a standstill, and long queues built up on the Swiss motorways and main roads, while the border police scrutinized the people passing through. The German border commuters were infuriated about the additional time they spent on their way home, and so were the many Belgian and Dutch holidaymakers who wanted to return home using the German motorways. Swiss people accustomed to do their shopping in German supermarkets reacted to this obstruction to free travel by refraining from shopping in Germany; sales in supermarkets and shops immediately dropped by $20 \%$ and more - not to the pleasure of the shop owners. This incident, which was discussed on high political levels, demonstrates the degree to which the Swiss border is geared to free movement.

German-Swiss relations have been restored since, but a certain malaise remains. It is enhanced by a contention concerning Zurich airport where, traditionally, most planes landed from the north (Figure 4), flying only $700 \mathrm{~m}$ above ground over numerous settlements on German territory, less than $20 \mathrm{~km}$ away. This landing regime had been agreed upon in 1984. The populations in the area concerned had been expressing their dissatisfaction for many years, but neither the German authorities nor the Swiss side (Zurich airport and the Canton of Zurich) had taken the complaints about the noise seriously, until Germany denounced the agreement in 2000. In the following year, the German and 


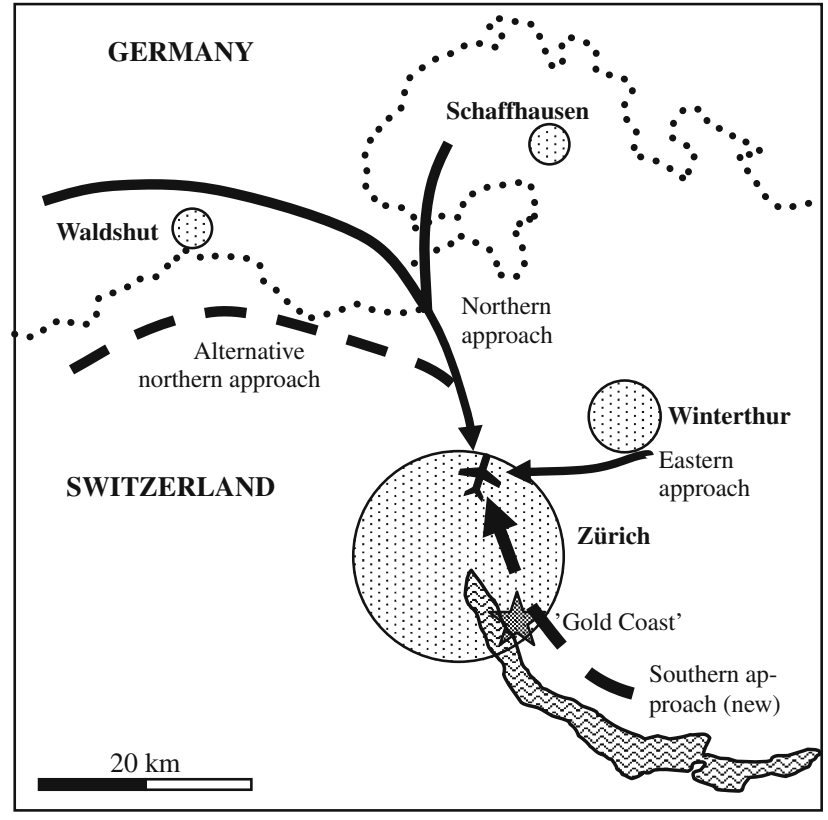

Figure 4. Approaches to Zurich airport.

Swiss transport ministers concluded a new bilateral treaty, which obliged Switzerland to reduce the number of landings from the north. However, Zurich airport and the Canton of Zurich refused this agreement, and the Swiss parliament rejected it in 2003. As a consequence, Germany enforced unilateral measures and restricted the number of approaches from the north. Most flights were therefore compelled to land from the south, approaching over the densely populated Zurich conurbation (including the "gold coast"), a solution the inhabitants concerned did not appreciate. The planes land from 6 a.m. onwards; the noise of low-flying airplanes is admittedly not very pleasant at this time of the day. Popular protests manage to keep the issue on the political agenda, and solutions (including an alternative northern approach or landing from the east) are actively studied. Opposition from the population in both regions concerned is strong, but eventually there may be little chance to turn the tide. The other alternative, landing from the east, is critical because of the topography - and because the population concerned has also manifested its discontent.

The case of Zurich airport may be an individual example, but it demonstrates to what extent boundaries can be useful to safeguard the quality of life of a region although in fact another region saw its quality of life curtailed. National legislation and competence in this case helped the population of a periphery (in Germany) to override the economic interests of a centre (in Switzerland). National sovereignty can be important when it helps to defend specific regional interests and secure votes for the next elections. It is true that airports inside a country are confronted with the same issues. The case of Frankfurt airport has often been quoted, where the populations had protested against the noise but not been considered. The example of Zurich airport also demonstrates that refusing to talk to the neighbour in the search for a solution does not pay. The current situation is much worse than it would have been under the regime of the German-Swiss treaty.

Switzerland is a small countries, densely populated and with intensive land use. There is little space for large airports. Basle airport (called EuroAirport) is situated in France, $3 \mathrm{~km}$ from the Swiss border and jointly operated by the French and the Swiss since its construction in 1946. An international (extraterritorial) road links its Swiss section to Basle, whereas the French section is connected to the regular road system. Crossing the border is only possible on foot, inside the airport (public area). Basle airport serves the three countries of the trinational Basle conurbation and represents a tendency of denationalisation in air traffic (Knippenberg and Markusse, 1999, p. 11). "Due to the complicated diplomatic structure of the airport, it has three airport codes: BSL (BaSeL) is the Swiss code, while MLH (MuLHouse) is the French code and EAP (EuroAirPort) is the international code" (http://euroairportbasel-mulhouse-freiburg.iqnaut.net/).

Geneva airport is located in Switzerland but right on the French border. Although it is a Swiss run institution, it has a French sector and can therefore be used for internal transfers by passengers flying between two French cities via Geneva. Both Basle and Geneva airports have had no problems with the neighbouring countries whose populations benefit directly from these two airports.

The Zurich airport issue is not really a boundary problem but rather of a politico-diplomatic nature. Air traffic is subject to different laws and rules from land transport, as the vertical dimension, the wind situation, the angles of approaching an airport etc. have to be taken into consideration. The nationalist feelings that lie behind the problem demonstrate that talking to each other and taking the noise problem seriously could be a step on the way to a solution - arrogance (as practiced by the Swiss side) is not a good attitude. This also holds good for relations with the Swiss population concerned by the new régimes.

\section{Shopping on the Swiss-Italian border}

Shopping across state borders means to take advantage of differences in price levels as well as of the range and quality of products. Customs regulations usually limit the quantities to be imported (in particular alcoholic beverages and tobacco); temporary restrictions may be imposed in sensitive fields such as fresh meat, fruit and vegetables. Shopping patters in border areas are usually fairly stable, although economic or politico-administrative changes may occasionally modify or even reverse them. The upgrading of former internal borders to state boundaries (as has occurred in former Yugoslavia, Czechoslovakia and Soviet Union) has transformed traditional transborder relations into international interactions. "In the process, mutual cooperation and 
help across the formerly soft borderlines have been replaced by competitiveness between the bordering states" (Barbič, 2004, p. 215).

Shopping patterns are often asymmetric, given the unequal conditions on either side of the border (Leimgruber, 1987, pp. 157 ff.; Barbič, 2004, pp. 224 ff.). However, they are not static. Comparing the contents of identical shopping baskets has allowed to reveal such dynamics over the past 25 years on the Swiss-Italian boundary (Figure 5). Traditionally, many people from Ticino as well as from the city of Brig in the Valais would do some of their shopping in Italy (food, alcoholic beverages, clothing and shoes), and Italian border commuters would purchase certain items (in particular petrol, cigarettes, and chocolate) in Switzerland (Leimgruber, 1987, p. 159). It is true that the difference in price levels has diminished slightly, but it used to favour the Swiss going into Italy. Thus, in 1980, the prices in Switzerland were 63.7\% above those in Italy, while in 1997 the difference was still $36.2 \%$. Early in 2004, however, the situation had changed drastically: Italians in the border zone flocked into the shopping centres on the Swiss (Ticino) side of the boundary, places they rarely visited before. According to the manager of a large supermarket, their number had increased by about $20 \%$ in the first three months of 2004. More unusual, Italians not only go for food but also for clothing - the trend has reversed. When prices were compared between two shopping centres in Switzerland and Italy it was found that the same goods cost $17 \%$ more in the Italian city of Como, compared to the Swiss town of Chiasso (Swiss TV 10 vor 10 News magazine, March 15, 2004). There are two reasons for this difference. On the one hand, inflation in Italy has been $4 \%$, whereas in Switzerland it oscillated between $-0.1 \%$ and $0.2 \%$ in the same period. Prices in Italy rose significantly as a consequence of the change from the Lira to the Euro (obviously shop owners profited from this move to adjust their prices upwards). A second reason can be found with the evolution of the exchange

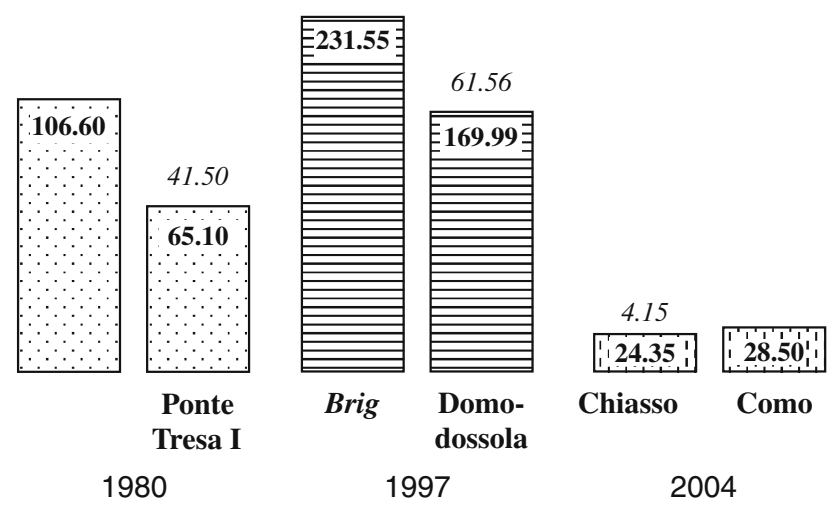

Figure 5. Shopping baskets: price variations 1980-2004. Explanations: In every year, an identical shopping basket was purchased on the Swiss and on the Italian side of the border. The price (in Swiss Francs) is indicated inside the column. The figure in italics shows the price difference, i.e. the advantage of shopping in Italy (1980 and 1997) or Switzerland (2004). rate, a strong Euro favouring purchases in Switzerland. This situation, however, will certainly not remain stable. Economic fluctuations are impossible to predict with some precision, hence the retail sector in border areas will remain highly volatile.

\section{Switzerland in Europe}

The examples discussed above at some length, demonstrate the fragility in the context of national boundaries. As a landlocked state, Switzerland has always depended on good relations with her neighbour countries, and as an island in the EU, this is even more the case: good relations with Brussels are as important as with the neighbours. It is true that Switzerland has tried to overcome the drawbacks of her geographical situation at an early date already: as a member of EFTA (1958), she cooperated closely with seven partner-countries (Austria, Denmark, Finland [associated member], Iceland, Norway, Sweden, and the UK) to promote free trade. In 1972, she concluded a free trade agreement with the EEC, thus widening the opening between the community and herself. The continuing enlargement of the EEC, which became the EC in 1993, put Switzerland under increased pressure and, following the accession of Austria in 1995, the country became an island inside the EU. The attempt at partially reducing the isolation by joining the treaty on the European Economic Area (EEA) failed in 1992 when the Swiss people rejected it by an extremely narrow majority (50.3\% against, $49.7 \%$ in favour, with a difference of only 23,836 votes). The enlargement of the EU in May 2004 has aggravated the situation by adding more partners to future negotiations. Unless the country eventually joins the Union, it will have to coexist through special treaties and agreements concluded between Berne and Brussels.

Bilateral contacts had in fact started immediately after the failure of the EEA-referendum. Formal negotiations started in 1994, the seven agreements were signed in 1999, and ratified by a referendum in Switzerland in May 2000. Among the seven issues covered, three were particularly delicate matters: the free movement of persons, trade in agricultural products, and public procurement; the four remaining topics were less controversial (land transport, air transport, research, and technical barriers to trade). Although nationalist parties were strictly opposed to the agreement, Swiss voters approved it with a $67 \%$ majority. To fully appreciate this result, one must remember that immigration and the presence of foreigners has been a controversial issue since the $1960 \mathrm{~s}$, and that xenophobia is a widespread phenomenon.

Currently, about $20 \%$ of the resident population in Switzerland (i.e. 1.4 millions) have a foreign passport (Table 1), although only about half of them may be true immigrants whereas the other half have been born in the country (second and third generation foreigners). The complicated naturalization policy renders the (statistical) 
Table 1. Foreign residents in Switzerland.

\begin{tabular}{llc}
\hline Year & Number & $\begin{array}{c}\% \text { of resident } \\
\text { population }\end{array}$ \\
\hline 1850 & 72,000 & 3.0 \\
1900 & 383,000 & 11.6 \\
1910 & 552,000 & 14.7 \\
1941 & 224,000 & 5.2 \\
1950 & 285,000 & 6.0 \\
1970 & $1,003,000$ & 16.2 \\
1980 & 920,000 & 14.5 \\
1990 & $1,245,000$ & 18.1 \\
2000 & $1,490,000$ & 20.5 \\
\hline
\end{tabular}

reduction of the numbers of foreigners difficult (Leimgruber, 2002). Currently, discussions revolve around refugees and the asylum legislation, illustrating the ambiguous attitudes many Swiss cultivate towards the "Others".

This first bilateral agreement, named Bilateral Treaty I, came into force in June 2002. It benefited the Swiss economy through improved access to goods and service markets as well as to labour. It also applies to the new member states of the European Union. ${ }^{3}$

In June 2001, twelve months before the implementation of the Bilateral Treaty I, Switzerland and the EU agreed on a second round of negotiations, which began in July 2002. Talks this time included ten topics, seven of which were common concerns and leftovers from the previous round (services; pensions; processed agricultural products, education, occupational training, youth, media; statistics; environment). The remaining three issues fell into two parts: Swiss concerns were increased cooperation in the fields of justice, police, asylum and migration (association to the Schengen/Dublin acquis), where's the EU was interested in the taxation of savings and the fight against fraud. In this latter category figured the most delicate issue, Swiss banking secrecy. Negotiations ended in 2004, the Swiss Parliament approved the treaty, and on June 5, 2005, the Swiss people also accepted the Schengen part of the agreement (the only one to be voted upon) with a $54.6 \%$ majority. Currently, only two out of the ten accords are in force (processed agricultural products, taxation of savings), the others still await ratification by the EU and Switzerland.

\section{Conclusion: On the persistence of boundaries}

To break a hole in a prison wall is a risky undertaking, and nobody knows to what extent it will succeed. Opening political boundaries to increased mobility and exchange (of goods, capital, and people) does not automatically lead to a win-win situation. The People's Republic of China has engaged in the delicate balancing act of opening the country and at the same time maintaining a substantial degree of control. Switzerland strives to stay outside the European Union and yet cooperate as far as possible as a non-member. These examples (to which others could be added) suggest that to some extent boundaries are prison walls, and they prompt the following two questions: Are boundaries essential to human societies (a necessary evil) or can (should) they be abolished? Will human coexistence be easier or more difficult without borders?

The Iron Curtain was to a large extent a material wall and the countries east of it were prisons - this was the western perception. As is well known, it was not completely sealed but had holes in it - man-made holes in the numerous tunnels dug in Berlin, institutional holes in the bureaucracy, and "human" holes in the degree of attention border posts sometimes paid to people wanting to cross the border. Legal departure was difficult but not entirely impossible. Without going into details, Skalnik (1994, p. 391) remarks: "I found the 'hole' in the curtain in Romania". Communist Yugoslavia (situated outside the Soviet realm) seems to have acted as a sort of channel for escape for many people.

Whether boundaries are prison walls or not is to some extent also a matter of individual perception and attitude. People may be proud to declare that they had never been abroad, although there would be no major obstacles. Others, on the other hand, will feel an urge to leave their country and experience the world outside. Modern mobility has made it possible - both physically and virtually. However, there is a strong tendency worldwide to build new walls, more or less visible. Tourist visa, biometric data in the passport, digital images and fingerprints taken at the crossing point are bricks towards a wall that impedes the free mobility most of us enjoyed in the late 20th century. The EU seeks to protect its territory from unwanted immigrants, Israel is building its wall against the Palestinians, the Korean DMZ remains an almost impermeable barrier, the US-Mexico boundary is almost an Iron Curtain, ${ }^{4}$ and so on. In 1999, the mayor of a small Czech town ordered the construction of a concrete wall between a Roma quarter and the rest of the city because of noise and different lifestyles - a decision that provoked a personal intervention by the Czech president Vaclav Havel. What can be prevented nationally cannot be stopped once the international boundary is concerned: Israel does not feel bound by the verdict of the International Court of Justice (July 9, 2004) concerning its wall against Palestine.

We have to be conscious of the ambiguity of borders. What can be affirmed with certainty is that there will be no world without boundaries. They are a necessity in order to organize space, time and society. What is at stake is the degree to which they ought to separate different areas, periods, and groups. Crossing the Rhine into Germany, the Karst into Slovenia, or skiing in an international skiing arena does not mean a change of landscape, not even of the fundamental culture. The limit between the middle Ages and the Renaissance is diffuse, and clear-cut lines do not separate social groups either. 
Are boundaries essential? They are clearly superfluous when they deprive humans from interacting with each other. To keep a child confined at home comes close to isolate an entire country with its population from the rest of the world. Boundaries may designate differences, but they must not be barriers. Learning another language signifies to make a hole in the prison wall of one's culture, although one does not become a member of that culture. Shopping and working on the other side of the border is an indicator of the material advantage offered by the boundary but also of immaterial ties that exist across it. Boundaries are rarely sharp; they tend to be blurred, indistinct. It is therefore wrong to be the prisoner of borders.

Prison walls may look solid, but they have (invisible) holes. Nelson Mandela testifies their permeability when, in his autobiography, he tells to what extent and by which means information was smuggled in and out of the high security prison on Robben Island (Mandela, 1994, pp. 485, 509, 568). Further proof is furnished by the collection of essays written in the same prison by a number of inmates in 1976 and 1978 and subsequently smuggled out (Maharaj, 2001). There is no such thing such as absolute separation, not even a high security prison can guarantee it. We cannot be total prisoners of borders but only partial ones.

Boundaries and prison wall are a relative concept: "No boundaries, no barriers; none in life, as there are none in nature. Einstein's life and his work were so mutually resonant that we recognize both to have been carried on together in the service of one grand project the fusion into one coherency. There were also no boundaries or barriers between Einstein's scientific and religious feelings" (Holton, 2003, p. 30). "Prison walls" primarily exist in our heads.

Will human coexistence be easier without borders? Boundaries stand for diversity, and diversity (in political systems, culture, social organization) is the lifeblood of humanity, just as biodiversity is essential to the ecosystem. To reduce humans to an amorphous mass in a borderless world is not only impossible; it is absolutely undesirable. The many processes in economy and politics, the information revolution and the ease of travel (which can be summed up under the term of globalization) have brought humans closer together. They have also increased the power of a few to influence the life of many. The divisive role of state borders has been reduced, but boundaries continue to be one of the characteristics of the state. It can be contended that human coexistence owes a lot to the existence of boundaries, because they allow us to see and recognize the advantages of differences and judge for ourselves on which side of a border life is better. We cannot live in an unorganized world, hence the "prison walls" must continue to exist. However, holes in them are essential for humanity.

Transborder cooperation is therefore an imperative, and it can be an important element in a peace process where a boundary is still prone to conflict. It is a demanding task, and policy decisions must consider many options: taking a truly regional perspective (not restricted by nationalistic considerations), recognizing that the two sides complement rather than compete with each other, allowing for flexibility, making efforts to understand the specific situation of borderlands, employing contextual (or pragmatic) approaches to problem solving (see Wright and Pavlakovich-Kochi, 2004). It is a creative task, requiring understanding, tact and sensitivity. As a result, people will discover that there are indeed beneficial holes in the prison wall.

\section{Notes}

1. We refer to legal trade, excluding smuggling which is practised all over the world and has a very strong local and regional component, although it has to do with national legislation. Smugglers have their own culture and consider their activity as normal labour, although they may sometimes also have rebelled against the authorities (Girtler, 1992, p. 193 ff.).

2. The former boundary between the Kingdom of the Two Sicilies and the Papal State lives on as the northern limit of the Mezzogiorno, the South Italian assisted region.

3. The free labour mobility clause (to formally include the ten new member states that had joined the EU in 2004) was submitted to the Swiss voters on September 25,2005 and accepted by a majority of $56 \%$.

4. Although this boundary is internal to the North American Free Trade Agreement (NAFTA), it obstructs the free movement of Mexicans to the United States. This demonstrates that free trade agreements are a macroeconomic tool and do not necessarily benefit the ordinary people.

\section{References}

Barbič A., 2004: Perceptions of new realities along the SlovenianCroatian borders. In: Pavlakovich-Kochi, Morehouse, B.J. and Wastl-Walter D (eds.), Challenged borderlands. Transcending political and cultural boundaries. pp. 115-235. Border Regions Series, Ashgate, Aldershot.

EU 2003: Promoting Language Learning and Linguistic Diversity: An Action Plan 2004 - 2006 (http://europa.eu.int/comm/education/ doc/official/keydoc/actlang/act lang en.pdf; 10.07.2004).

Foucher M., 1988: Fronts et frontières. Un tourd du monde géopolitique. Fayard, Paris.

Girtler R., 1992: Schmuggler. Von Grenzen und ihren Überwindern. Veritas, Linz.

Guichonnet P. and Raffestin C., 1974: Géographie des frontières. PUF, Paris.

Hajdú Z., 2004: Renewal of cross-border cooperation along the Hungarian-Croatian border. In: Pavlakovich-Kochi, Morehouse, B.J. and Wastl-Walter D (eds.), Challenged borderlands. Transcending political and cultural boundaries. pp. 109-122. Border Regions Series, Ashgate, Aldershot.

Holton G., 2003: Einstein's Third Paradise, Daedalus, Fall, pp. 26-34 (http://www.aip.org/history/einsteins-third-paradise.htm, 30.04.04).

Knippenberg H. and Markusse J., 1999: $19^{\text {th }}$ and $20^{\text {th }}$ century borders and border regions in Europe: some reflections. In: Knippenberg 
H., and Markusse J. (eds.), Nationalising and denationalising European border regions, 1800-2000: views from geography and history. pp. 1-19. Geojournal Library 53, Kluwer, Dordrecht.

Lee B.T. and Bahrin T.S., 1998: Wither the borders? Towards a new dimension of geographical differentiation. In: Lee B.T., and Bahrin T.S. (eds.), Vanishing borders: the new international order of the $21^{\text {st }}$ century. pp. 3-12. Ashgate, Aldershot.

Leimgruber W., 1980: Die Grenze als Forschungsobjekt der Geographie Regio Basiliensis XXI(1/2): 67-78.

Leimgruber W., 1987: Il confine e la gente. Interrelazioni spaziali, sociali e politiche fra la Lombardia e il Canton Ticino. Collana dell'Istituto di Scienze Geografiche dell'Università di Parma, vol. 7. Varese, Lativa.

Leimgruber W., 1999: Border effects and the cultural landscape: the changing impact of boundaries on regional development in Switzerland. In: Knippenberg H., and Markusse J. (eds.), Nationalising and denationalising European border regions, 1800-2000: views from geography and history. pp. 199-221. Geojournal Library 53, Kluwer, Dordrecht.

Leimgruber W., 2002: La politica immigratoria in Svizzera. In: Meneghel G.B., and Lombardi D. ( (eds.), Immigrazione $e$ territorio. pp. 29-42. Patron Editore, Bologna.

Leuthardt B., 1999: An den Rändern Europas. Berichte von den Grenzen. Rotpunktverlag, Zürich.

Maharaj, M., (ed), 2001: Reflections in prison. Zebra and Robben Island Museum, Cape Town.

Mandela N., 1994: Long walk to freedom. Abacus, London.

Morehouse B.J. (2004): Theoretical approaches to border spaces and identities. In: Pavlakovich-Kochi V., Morehouse B.J. and WastlWalter D. (eds.), Challenged borderlands. Transcending political and cultural boundaries. pp. 19-39. Border Regions Series, Ashgate, Aldershot.

Mrohs E. and Heukels J.M., 1970: Die Grenze - Trennung oder Begegnung, S'Gravenhage, Forschungsgesellschaft für Agrarpolitik und Agrarsoziologie.

Orwell G., 1954: Nineteen eighty-four. Penguin, Harmondsworth.

Pounds N.J., 1963: Political Geography. McGraw-Hill, New York.

Raffestin C., Guichonnet P. and Hussy J., 1975: Frontières et sociétés. Les cas franco-genevois. Lausanne, L'Age d'Homme.

Rambaud P., 2004: Europe - D.Institutions européennes, Encyclopédia Universalis, CD-Rom V.9.

Sack R.D., 1986: Human territoriality. Its theory and history. Cambridge University Press, Cambridge.

Shiva V. (1993). Monocultures of the mind. Perspectives on biodiversity and biotechnology. Zed Books \& Penang: Third World Network, London \& New York.

Shiva V., 1996: The war against species. In: Miller G.T. Jr. (ed.), Living in the environment. pp. 298-299. (7th ed.) Wadsworth, Belmont.

Shalnik P., 1994: State borders as factors mitigating cooperation and coexistence. In: Gallusser W.A., Bürgin M., and Leimgruer W. (eds.), Political boundaries and coexistence. pp. 390-394. Peter Lang, Berne.

van Houtum H., 1998: The development of cross-border economic relations. Dissertation Series, 40. Centre for Economic Research, Tilburg University, The Netherlands.

Wright B.A. and Pavlakovich-Kochi V., 2004: Epilogue: implications for policy- and decision-making. In: Pavlakovich-Kochi V., Morehouse, B.J. and Wastl-Walter D (eds.), Challenged borderlands. Transcending political and cultural boundaries. pp. $295 \mathrm{f}$. Border Regions Series, Ashgate, Aldershot. 